\title{
ST-Segment Elevation Myocardial Infarction: Door to Balloon Time Improvement Project
}

\author{
Saad Al Bugami ${ }^{\mathrm{a}, \mathrm{d}}$, Jamilah Alrahimi ${ }^{\mathrm{b}}$, Abdullah Almalki ${ }^{\mathrm{b}}$, Farqad Alamgerc, \\ Ahmed Krimlya, Wail Al Kashkaric
}

\begin{abstract}
Background: The purpose of this quality improvement project was to evaluate prospectively the causes of delay for patients with acute ST-segment elevation myocardial infarction (STEMI) requiring primary percutaneous coronary intervention (PCI) upon arrival at the emergency department (ED) and implement recommendations to reduce delays and analyze the impact of recommendations to reduce the door-to-balloon (D2B) time in a newly established cardiac center (King Faisal Cardiac Center (KFCC)). Primary PCI has developed as an effective treatment strategy for acute STEMI, the survival rate and patient outcome are however dependent on the time to treatment. The international benchmark for all programs dealing with acute coronary syndrome patients suffering from STEMI has been established as 90 minutes or less from the time the patient arrives at the hospital to the opening of the affected vessel in the cardiac catheterization laboratory "door-to-balloon time" or D2B. In KFCC during the year 2014, the STEMI, D2B time of $\leq 90$ minutes was achieved in $25 \%$.
\end{abstract}

Methods: We conducted a single center prospective data collection for consecutive patients presenting with STEMI within 24 hours of the onset of chest pain between January 2015 and December 2015. The boundaries of the process began when the patient entered the emergency department and ended when the balloon was inflated during the PCI. Certain well-defined metrics were chosen to drive the change and identify the defect.

Results: A total of 37 patients presented with STEMI. The number of patients who achieved the target D2B time $\leq 90$ minutes was 20 (54\%). Nine patients $(24.4 \%)$ had D2B time between 91 and 120 minutes and eight patients $(21.6 \%)$ beyond 120 minutes. The delays were due to late identifications of patients with chest pain as well as in obtaining ECG, activation and transport to the catheterization

Manuscript accepted for publication July 13, 2016

aKing Saud bin Abdulaziz University for Health Sciences; King Faisal Cardiac Center, King Saud bin Abdulaziz Medical City, Jeddah, Saudi Arabia

${ }^{b}$ King Saud bin Abdulaziz University for Health Sciences; King Abdulaziz Medical City, Jeddah, Saudi Arabia

${ }^{\circ}$ King Faisal Cardiac Center, King Abdulaziz Medical City, Jeddah, Saudi Arabia

${ }^{\mathrm{d} C o r r e s p o n d i n g ~ A u t h o r: ~ S a a d ~ A l ~ B u g a m i, ~ K i n g ~ S a u d ~ b i n ~ A b d u l a z i z ~ U n i v e r-~}$ sity for Health Sciences; King Abdulaziz Medical City, King Faisal Cardiac Center, Jeddah 21423, Saudi Arabia. Email: Bogamisa@ngha.med.sa

doi: http://dx.doi.org/10.14740/cr476w laboratory.

Conclusion: There was a measurable improvement up to $54 \%$. Several factors have contributed to the delays in achieving the goal standard of above $90 \%$; these include late identifications of patients with STEMI, delays in obtaining the ECG, activation of the catheterization laboratory and delay of patients' transportation.

Keywords: Door to balloon; ST-segment elevation myocardial infarction; Primary percutaneous intervention

\section{Introduction}

Many scientific bodies like the American College of Cardiology (ACC), American Heart Association (AHA), and the European Society of Cardiology (ESC) recommend that all ST-segment elevation myocardial infarction (STEMI) patients should undergo rapid evaluation for reperfusion therapy and have reperfusion strategy implemented promptly after contact with the medical system $[1,2]$.

Primary percutaneous coronary intervention (PCI) has to be performed in a timely fashion and door-to-balloon (D2B) time benchmark is $\leq 90 \mathrm{~min}$ in PCI capable hospital. This strategy is supported by a meta-analysis of 23 trials showing an absolute $2 \%$ reduction in mortality with primary PCI compared with fibrinolytic therapy [3]. Many trials have demonstrated that D2B time $\leq 90 \mathrm{~min}$ is associated with smaller infarct sizes, fewer major adverse cardiovascular events, and better long-term survival [3-8]. International guidelines in the management of patients with STEMI recommended several performance measures to monitor the quality of delivered patient care [9]. Of particular interest are the D2B time (arrival at hospital to primary PCI) and overall health care system delay (first medical contact to reperfusion); both of these are acknowledged as valuable performance indicators [10-13]. In the year 2014, King Faisal Cardiac Center (KFCC) had achieved D2B time of $\leq 90 \mathrm{~min}$ in $25 \%$ of patients.

\section{Methods}

King Faisal Cardiac Center is one of the primary centers which perform primary PCI as treatment for STEMI in Jeddah, Saudi Arabia. Primary PCI is the routine treatment in KFCC for 


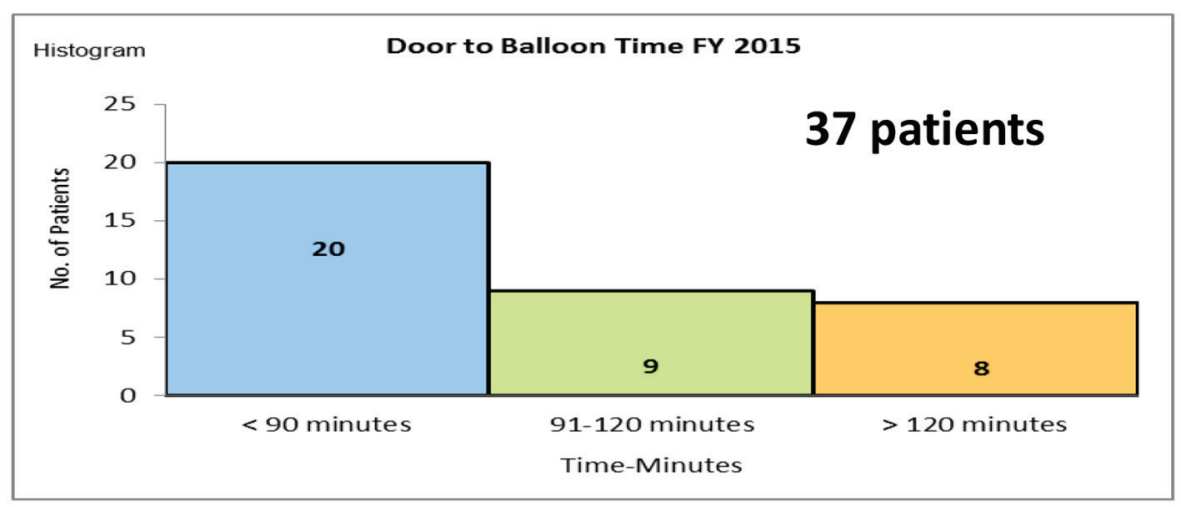

Figure 1. The total number of STEMI patients and the D2B time in each group.

eligible STEMI patients $24 \mathrm{~h}$ a day, 7 days a week. Guidelines recommend that $\mathrm{D} 2 \mathrm{~B}$ time should be $90 \mathrm{~min}$ or less. To meet this goal, multidisciplinary team was selected to improve D2B time. The team consisted of representatives from the cardiac catheterization laboratory (CCL), emergency department (ED), clinical informatics, pharmacy, nursing services, quality management department, and physician leadership.

The project was a prospective data collection for consecutive patients presenting with STEMI within $24 \mathrm{~h}$ of the onset of chest pain between January 2015 and December 2015. The project included all patients above the age of 18 years presenting to ED with acute cardiac chest pain within $24 \mathrm{~h}$ and ECG changes demonstrating ST-segment elevation or new left bundle branch block (LBBB). This meant that several patient groups were excluded from the project, including those transferred from another hospital, those less than 18 years of age, those receiving comfort measures only, those receiving fibrinolytics prior to PCI, and those receiving PCI as a non-primary procedure. The boundaries of the process began when the patient entered the ED and ended when the balloon was inflated during the PCI. The D2B time was broken down into the following clinically relevant intervals: door to ECG time (goal $\leq 10 \mathrm{~min}$ ), ECG to catheterization laboratory team activation time (goal $\leq 5 \mathrm{~min}$ ), catheterization laboratory activation to patient arrival to catheterization laboratory time (goal $\leq 45 \mathrm{~min}$ ), and arrival to catheterization laboratory to balloon time (goal $15 \mathrm{~min}$ ) and $15 \mathrm{~min}$ was allowed for system delays. Data were collected and analyzed, and feedback was provided through collaborative meetings with ED, emergency medical service (EMS) and CCL, hospital leadership and staff. Action plans and interventions were put in place to drive the changes in the above metrics which resulted in change in flow of care and improved communications among stake holders.

\section{Results}

The total number of eligible patients for primary PCI who met the inclusion criteria during the study period was 37 (Fig. 1). The number of patients who achieved the target D2B time of 90 min or less was 20 (54\%) (Fig. 1). Nine patients (24.4\%) had D2B time between 91 and $120 \mathrm{~min}$ and eight patients $(21.6 \%)$ beyond $120 \mathrm{~min}$. There was a noticeable seasonal variation in the number of patients presenting with STEMI, with the highest presentation recorded in the third quarter of the year, a total

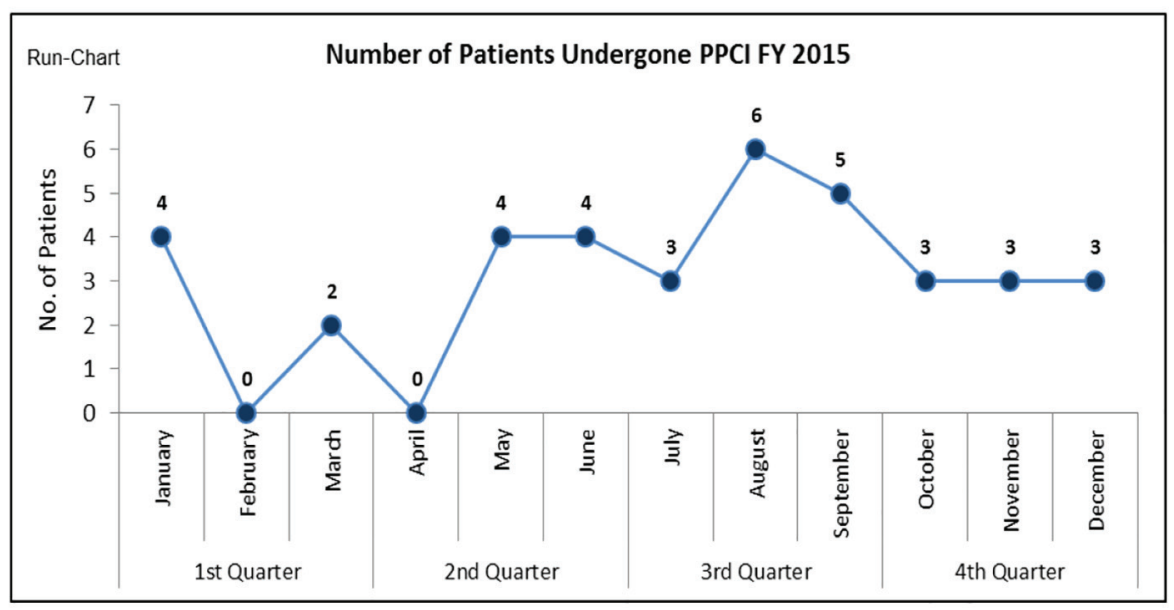

Figure 2. The distribution of patients throughout the year. 


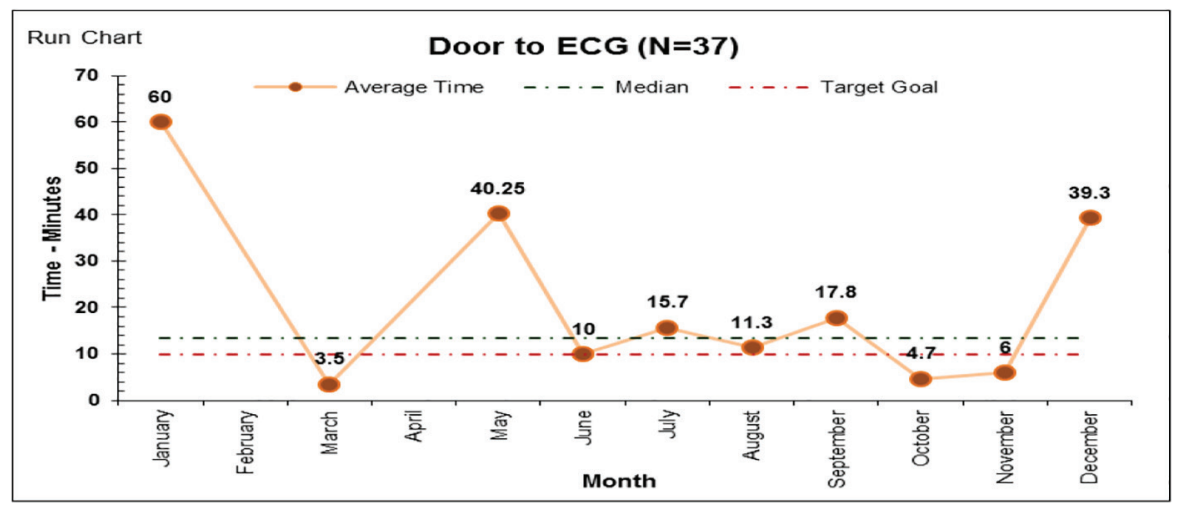

Figure 3. The monthly mean time of door to ECG time consistently above target of less than 10 min.

of 14 patients (37.8\%) (Fig. 2).

\section{Discussion}

The results of this analysis convey perceptions into "real life fact" in the management of STEMI patients in a newly established cardiac center in Saudi Arabia. International guidelines in the management of patients with STEMI recommend several performance measures to monitor the quality of delivered patient-centred care [9]. Of particular interest are the D2B time and overall health care system delay (first medical contact to reperfusion); both of these are acknowledged as valuable performance indicators [10-13]. Our data demonstrate only 54\% achievement in meeting the D2B treatment time of less than $90 \mathrm{~min}$.

Several factors have contributed to the delays in achieving the goal. Failure to promptly triage and identify STEMI patients has contributed to the major delay in D2B time. The reasons ranged from patients not declaring themselves, lack of awareness to atypical presentations (Fig. 3).

An unexpected finding in this study was the delay of the process of catheterization laboratory activation and transportation from ED to the catheterization laboratory which is located in a different building; this was longer than expected and shown in Figures 4 and 5, respectively. Variation in the mean time required to open the infarct-related artery once the patient arrived to the catheterization laboratory is the least to contribute to the delays as shown in Figure 6.

In the Gulf Registry of Acute Coronary Events (Gulf RACE 2), 1,832 were admitted to the surveyed hospitals with CCL facilities. Only 198 (10.8\%) patients received primary PCI, of whom only $55 \%$ achieved D2B time $\leq 90 \mathrm{~min}$.

In that STEMI cohort of 93 patients from Saudi Arabia, timely primary PCI of less than 90 min was achieved in $40.9 \%$ of patients [14].

The similarities of these results demonstrated in several hospitals in Saudi Arabia require a collaborative action among health care stake holders to implement proper strategies to improve the local practice and minimize D2B time. The key strategies to improve D2B time based on quality improvement initiative include education campaign for ER staff, immediate activation of catheterization laboratory by ED physicians, establishment of a single call system for activating catheterization laboratory, use of data monitoring and prompt data feedback to ED and catheterization laboratory, development of a speedy referral mechanism to accept and transfer patients for primary PCI from nearby non-catheterization laboratory-based hospitals to increase the volume of patients and finally seeking of senior management support to implement organizational changes directed at improving the health care environment and fostering timely D2B in STEMI patients [15].

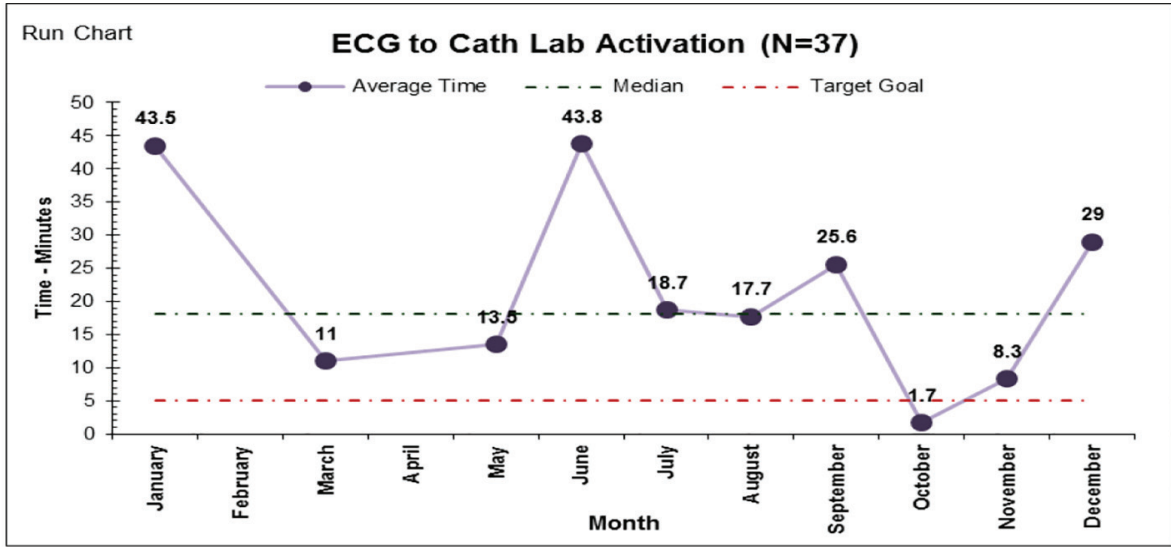

Figure 4. The mean time to activate the catheterization laboratory. 


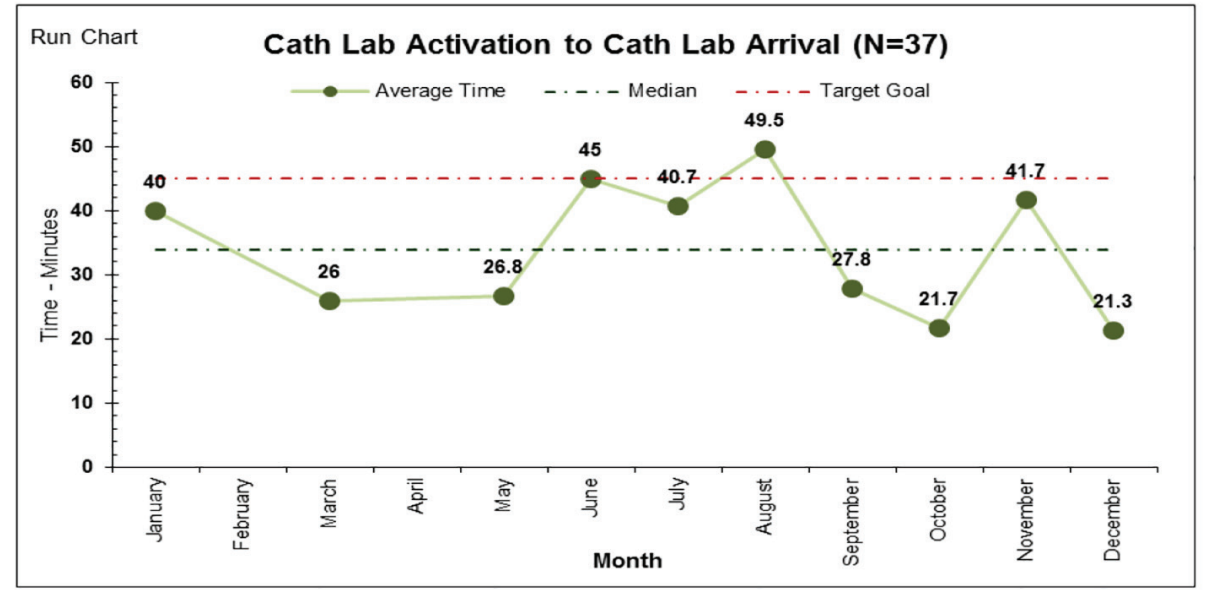

Figure 5. Monthly mean time from catheterization laboratory activation till patient arrival.

\section{Conclusion}

Quality improvement initiative for medical policies and procedures is a continually evolving endeavour in all medical facilities that strive to deliver excellent care.

Primary PCI is an effective treatment strategy for STEMI. Current guidelines for the treatment of STEMI recommend a D2B time of 90 min or less for patients undergoing primary PCI. D2B time has become a performance measure and is the focus of regional and national quality improvement initiatives [16]. Our experience at KFCC demonstrates the effectiveness and durability of process changes targeting timeliness of primary PCI. We were able to achieve overall significant decrease in the percentage of D2B time, despite the measurable improvement challenges remain. The process of quality improvement of D2B time continues to evolve.

\section{Limitations}

Single center data and small number of patients are limitations, and outcome data were not available as it was not a priority in this quality improvement study.

\section{Acknowledgments}

We would like to thank the staff of King Faisal Cardiac Center catheterization laboratory for collecting the data and Mrs Chona Barcelona from quality department for generating the graphs.

\section{Conflicts of Interest}

None of the authors have any declared conflicts of interest.

\section{Ethical Approval}

This project was deemed exempt from ethical approval as it is an improvement study and not a study on human subjects, and hence ethical approval was not required.

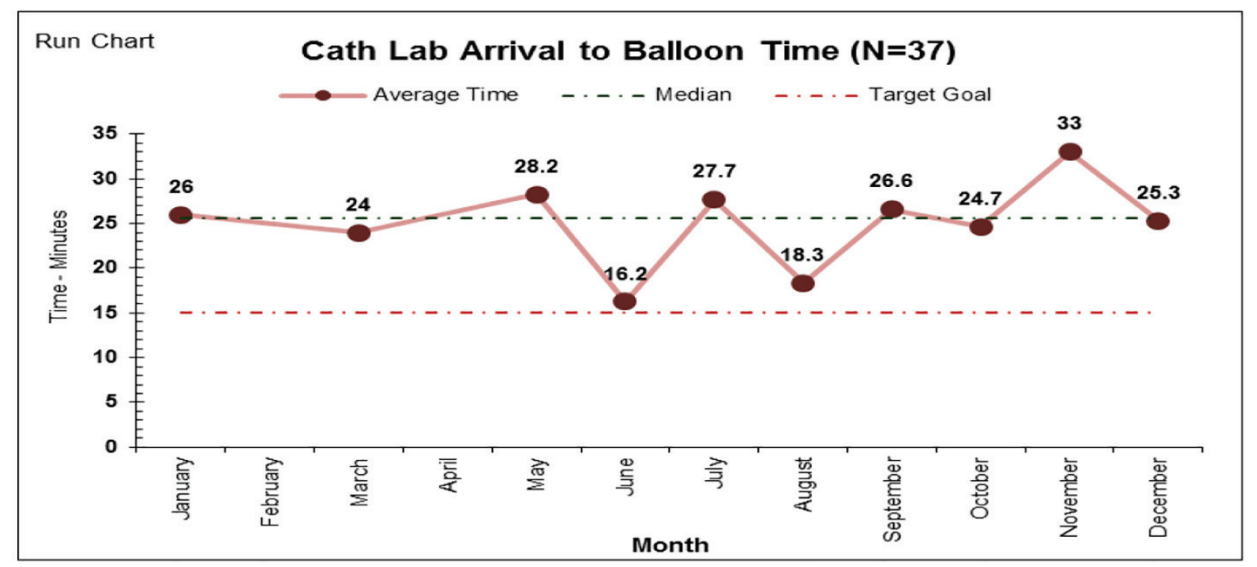

Figure 6. The time it took to open the infarct-related artery from patient arrival to the catheterization laboratory. 


\section{References}

1. Steg PG, James SK, Gersh BJ. 2012 ESC STEMI guidelines and reperfusion therapy: Evidence-based recommendations, ensuring optimal patient management. Heart. 2013;99(16):1156-1157.

2. Fox KA, Goodman SG, Klein W, Brieger D, Steg PG, Dabbous O, Avezum A. Management of acute coronary syndromes. Variations in practice and outcome; findings from the Global Registry of Acute Coronary Events (GRACE). Eur Heart J. 2002;23(15):1177-1189.

3. Keeley EC, Boura JA, Grines CL. Comparison of primary and facilitated percutaneous coronary interventions for ST-elevation myocardial infarction: quantitative review of randomised trials. Lancet. 2006;367(9510):579-588.

4. Dryja T, Kornacewicz-Jach Z, Goracy J, Przybycien K, Jodko L, Skowronek A, Kurowski M, et al. Treatment of acute ST-segment elevation myocardial infarction in West Pomerania province of Poland. Comparison between primary coronary intervention and thrombolytic therapy. Kardiol Pol. 2006;64(6):591-599; discussion 600-591.

5. Brodie BR, Hansen C, Stuckey TD, Richter S, Versteeg DS, Gupta N, Downey WE, et al. Door-to-balloon time with primary percutaneous coronary intervention for acute myocardial infarction impacts late cardiac mortality in high-risk patients and patients presenting early after the onset of symptoms. J Am Coll Cardiol. 2006;47(2):289295.

6. Cannon CP, Gibson CM, Lambrew CT, Shoultz DA, Levy D, French WJ, Gore JM, et al. Relationship of symptomonset-to-balloon time and door-to-balloon time with mortality in patients undergoing angioplasty for acute myocardial infarction. JAMA. 2000;283(22):2941-2947.

7. Kumbhani DJ, Cannon CP, Fonarow GC, Liang L, Askari AT, Peacock WF, Peterson ED, et al. Association of hospital primary angioplasty volume in ST-segment elevation myocardial infarction with quality and outcomes. JAMA. 2009;302(20):2207-2213.

8. Estevez-Loureiro R, Lopez-Sainz A, Perez de Prado A, Cuellas C, Calvino Santos R, Alonso-Orcajo N, Salgado
Fernandez J, et al. Timely reperfusion for ST-segment elevation myocardial infarction: Effect of direct transfer to primary angioplasty on time delays and clinical outcomes. World J Cardiol. 2014;6(6):424-433.

9. Terkelsen CJ. Time to treatment-door-to-balloon time is not everything. Herz. 2014;39(6):672-676.

10. Bradley EH, Nallamothu BK, Herrin J, Ting HH, Stern AF, Nembhard IM, Yuan CT, et al. National efforts to improve door-to-balloon time results from the Door-toBalloon Alliance. J Am Coll Cardiol. 2009;54(25):24232429.

11. Lassen JF, Botker HE, Terkelsen CJ. Timely and optimal treatment of patients with STEMI. Nat Rev Cardiol. 2013;10(1):41-48.

12. Rasmussen MB, Frost L, Stengaard C, Brorholt-Petersen JU, Dodt KK, Sondergaard HM, Terkelsen CJ. Diagnostic performance and system delay using telemedicine for prehospital diagnosis in triaging and treatment of STEMI. Heart. 2014;100(9):711-715.

13. Thorsted Sorensen J, Steengaard C, Holmvang L, Okkels Jensen L, Terkelsen CJ. [Primary percutaneous coronary intervention as a national Danish reperfusion strategy of ST-elevation myocardial infarction]. Ugeskr Laeger. 2013;175(4):181-185.

14. Shehab A, Al-Habib K, Hersi A, Al-Faleh H, Alsheikh-Ali A, Almahmeed W, Suleiman KJ, et al. Quality of care in primary percutaneous coronary intervention for acute STsegment -elevation myocardial infarction: Gulf RACE 2 experience. Ann Saudi Med. 2014;34(6):482-487.

15. Krumholz HM, Bradley EH, Nallamothu BK, Ting HH, Batchelor WB, Kline-Rogers E, Stern AF, et al. A campaign to improve the timeliness of primary percutaneous coronary intervention: Door-to-Balloon: An Alliance for Quality. JACC Cardiovasc Interv. 2008;1(1):97-104.

16. Ellahham Md S, Aljabbari S, Harold Mananghaya T, S JR, Al Zubaidi A. Reducing Door to- Balloon- Time for Acute ST Elevation Myocardial Infarction In Primary Percutaneous Intervention: Transformation using Robust Performance Improvement. BMJ Qual Improv Rep. $2015 ; 4(1)$. 